\title{
STUDY OF ACCELERATION PHENOMENA IN JAPAN
}

\section{AKIRA SAWADA, TOSHITAKE AMANO \& YOSHIAKI MAEDA}

Osaka University

Interests of modern developmental psychology in the secular changes of human beings have considerably increased in recent years. Ever since E. W. Koch in 1935 expressed his view in reference to the fact that the development of the human body had been accelerated along with one generation after another (13), and with another issue of reports by Prof. C. Bennholdt-Thomsen in Pediatrics of Köln University (Univ. of Cologne) in 1942, confirming the same acceleration under his own theory on the subject of "Acceleration Phenomena" (Akzeleration, Entwicklungsbeschleunigung) based on the gigantic statistical data (3), many specialists of psychology, pedagogy and medical sciences in Europe started their continuous study on the subject $(2,10,14,24)$; it can be well inferred that these acceleration phenomena showing a gradual distinction in Europe since 1840, although the actual transition somewhat differs one from another by the condition of each country, do not give any sign of coming to a standstill, neither does its tendency retreat in the least at present. These phenomena covering all the possible processes in both growth and maturity of the human body must, however, not be referred to any particular case, but ought to be dealt globaly with many complex facts observed from the viewpoints of the structural transition of the current human organism; the phenomena are considered possessing the following two basic factors for acceleration: (1) Acceleration in growth and (2) Acceleration in maturity with 'Vorverlegung' (shifting forward): the former is generally noticed by increase in height and weight, while the latter shows precociousness in sexual function and teething. The word 'Vorverlegung' denotes an earlier age than the normal age at which the outset of the bodily function takes place on the ontogenetic time axis; the acceleration in growth signifies not only the multiplied speed in the bodily growth but also so much increase in the tinal growth value in comparison with the statistical data obtained for the last and previous generations.

Application for Acceleration phenomena:

Two factors relating to the human bodily developments, in the terms of (1) Secular acceleration and (2) Developmental gradient phenomena are suggested for observation: the former gains speed difference in the human ontogenetic development between one generation and another on the same age, while the latter referring to the same generation and the same age, deals with such speed difference by taking into account racial and geographical differences and also those concerned with social status and occupation of family; each of the two cases has a fairly large variety produced by the different procedures thus applied, but these must be treated as a whole phenomenon; more definite data are given in the form of schema as follows:

(1) Secular acceleration covering speed differences in development on different generations on the same age, classified under the following items:

(a) Accelerated increase in height and weight of infants, school children and youths in the current generation. 
(b) Precociousness in teething.

(c) Precociousness in menarchical age.

(d) Precociousness in initial seminal discharge.

(e) Transition of the age of the lowest death rate to smaller figures, as from 13 to 11 in Europe (3).

(f) Transition of the age of the highest disease contraction rate to smaller figures as from 11 in 1925 to 8 in 1950 in Europe as applicable to St. Vitus's Dance (3).

(2) Developmental gradient phenomena covering speed differences in development on the same generation and the same age, classified under the following items:

(a) Accelerated increase in height and weight of children and youths at higher rate for urban areas than the speed for rural districts.

(b) More precocious sexual development of urban children on comparison with rural children.

(c) Earlier development of tecthing for urban children than the case with rural children.

(d) In the same urban area, more acceleration and precociousness is generally observed among the socially upper class children and youths than the case with the lower classes.

I. Certain Backgrounds of Acceleration Phenomena

In the post-war Japan, many problems pertaining to the young generations have been brought to the public attention; among them was the existing rapid elevation of the general physical standards among young men, together with the marked sexual precociousness among young women; on the other hand, the socio-economic developmental gradient has become more noticeable between the urban areas and the rural districts. A number of investigations and researches have been carried out, but within the sphere of the individual phenomena, and any attempts from the integral view-points in relation with acceleration phenomena were totally ignored.

American psychology and the kindred human sciences, in spite of a number of studies in correlation with intelligence and physical growth, have not yet developed this problem of acceleration phenomena: this was possibly due to the restricted common notion among scholars that none of such studies ought to have been made beyond the limit of its own; the relevant psychological studies, apart from its original object of setting up certain formulas by which to determine the relationship of the circumferential stimuli with the human conducts, seem to have lacked the sense of perspective with the resultant failure in viewing the whole of the human life for itself within the frame of the established cultural and historical circumstances. Generally speaking, there are certain facts that account for hindrance of the recognition of acceleration phenomena, as noted below in detail under (1) and (2):

(1) The first incorrect notion was no other than an immediate attribution of all the abrupt social changes and confusions to the post-war phenomena, with the resultant lack of the proper recognition of many more responsible factors, irrespective of the causes of the lost war.

In the post-war Japan, Japan encountered a number of changes and occurrences, calling for serious consideration among which were the increased juvenile delinquency, closer social intercourse between young men and women, more activities of women in the social and industrial circles with their claim for equal rights, and also the present democratised family con- 
stitution; all of these ought to have been taken as a consequence of the modernization of the industries, and this can be well compared with the developmental gradient phenomena among the young generation in Japan; in no way should the causes be attributed to the consequence of the lost war. The fact remains, however, that a very acute dislocation has been created between the pre-war and the post-war periods; there is no denial that Japan has developed her modern civilization far from autonomously, rather against the natural law of growth and maturity.

Now, taking it for granted that there is an inseparable relationship between the acceleration phenomena and the facts of modernization or urbanization, of which Bennholdt-Thomsen holds a very positive opinion (3), the elevation of the physical standards among the young generation in the post-war time, ought to be regarded as common a phenomenon in Japan as in all the high civilized countries or communities: in other words, the elevated physical standards cannot be fully explained by that well-known theory of biological mechanism only, which professes that any organism placed under such disadvantageous environment depriving its normal development and bringing it to the seriously depressed or impaired condition, would use very speedily its potential capacity as a immediate reaction on the improvement of the adverse environment $(1,10)$.

(2) Generally speaking, the recent psychology and pedagogy, despite the possession of a large number of affirmative data, seem to have solely adhered to the latent premises that the psycho-biological organization of the human organism does not change from its original statue on the transition of one generation to another, or any change of this sort, even if it does exist, would be of very little consequence. On the other hand, very few problems concerning this secular changes of the human being have hitherto been taken up for discusssion either from the theoretical or practical view-points, presumably for the reason that this sort of study does not accord with the established basic principle of psychology; many attempts so far made of governing and formulating the structure of personality within the sphere of the theories concerned with the biological organization of the human being, have flatly been denied and treated as a genuine biologism; this can be referred to the Spranger's psychology of adolescence, where he gives certain illustrations of extreme nature.

It is therefore very natural to conclude that Kretschmer and Conrad (8), in their constitutional typology, and also Zeller (25), in his developmental biology, could not play an important role in the system of the developmental, childhood and adolescence psychology.

Recent biological anthropology by Bolk, Portmann, Gehlen $(7,11,18)$ and other scholars is seriously being confronted with the theory of past anthropology that human being is clearly distinguished from animal by spirit and reason with the conclusion that the biological layers of personality are no other than a mere extension of animality; according to the former, the human being is an imperfect organism (Mängelwesen) and its characteristics can be collectively inferred with the following conceptions:

1) Maintenance of embryonic characteristics, from the morphological view-point (Bolk).

2) Slowness in the developmental speed before the pubescence age (Bolk, Portmann).

3) Secondary altricial* mammal as based on his theory that a human being is a precocial*

* "Altricial" translates the German Nesthocker, as contrasted with "precocial," which translates Nestflüchter (22). 
born one year too early, from the ontogenetic view-point (Portmann).

4) The superfluity of impulsive drive (Antriebsüberschuss), without security of instinct, that constitutes the human impulsive structure (Gehlen).

The above are the very high ideas all attempting to catch hold of the human characteristics that may exist before the time of formation of autonomic personality by taking into account the fact that a human being keeps a very long period of immature childhood; it is apparent that the revolution of living organism, multiplied by the continued development of culture and civilization, makes the period of the human childhood so much lengthened.

However, the theory of developmental acceleration phenomena is now found colliding squarely with the above-cited basic existential modes of the human being, in the viewpoint that the period of a human childhood is shortened by the acceleration in growth with 'Vorverlegung': this fact naturally leads to the conclusion that the acceleration phenomena should have been treated as an exceptional subject on some irregular human occurrences, and has thus hitherto been left alone uncared for without adequate comprehension in the light of the recent biological anthropology.

There naturally arises a question whether the existing acceleration phenomena constitute some serious obstacles in the human natural development, because of the loss of equilibrium of the innate system of personality against the living environment, or this is a more positive comprehensible problem regarded as a correct human phenomenon applicable to the historical status of the present world. This is a matter of future researches which may give a correct answer.

However, those particular phenomena, such as 'Vervorlegung' of sexual function, increase in height and weight, etc. should not be viewed from the same angle as on the usual human pathological phenomena, such as Pubertas praecox and Macromelia; those should be comprehended as one of the variants of the normal and correct development.

\section{Acceleration in Growth}

This is the subject now dealt with to see if any of the acceleration phenomena exists in Japan, and if it does, then to ascertain further the scope in which it has developed and the way it has been transitted: the following is a summary of the growth in height of school children: 1. Secular acceleration in height growth.

A general view of secular changes in average height of Japanese children is now given under (a) covering the gradual increase in the pre-war period: 1900 to 1939 ; (b) showing an abrupt drop in the standard height in 1948, due positively to the adverse food condition during and after the war and (c) giving a speedy recovery up to the pre-war time level in later years until now still keeping the continuous upward tendency; these are explained in detail under each heading as follows:

(a) Gradual increase in the prewar period: 1900 to 1939: This refers to the following Table 1 showing the average height increase of school children in 1900 and 1939 for comparison:

From the above, it can be noticed that for the year 1939, the increase in the standard height became so high compared with the records for 1900 that both boys and girls had overgrown by six months or more, with the tendency that for the children of higher age the increment difference was more noticeable: for instance, a boy of 14 in 1939 was well corres- 
Table 1. The Increment of the Height Growth during 39 Years in Pre-War Japan.

\begin{tabular}{r|cc}
\hline Age & Boy & Girl \\
\hline 6 & $2.1 \mathrm{~cm}$ & $3.3 \mathrm{~cm}$ \\
10 & $4.3 \mathrm{~cm}$ & $3.8 \mathrm{~cm}$ \\
12 & $3.9 \mathrm{~cm}$ & $5.8 \mathrm{~cm}$ \\
14 & $5.1 \mathrm{~cm}$ & $5.7 \mathrm{~cm}$ \\
\hline
\end{tabular}

Remarks: The above are the data obtained from Statistical Reports of School Hygiene by Ministry of Education, but no data for 1921, 19401947 are available.

ponding to a boy of 15 in 1900 , and a girl of 14 to a girl of 20 (15).

(b) Rapid decrease during the period: 1939 to 1948: No statistical figures are available for the years: 1939-1948: both exclusive. Table 2 given below covers the comparative data for 1939 and 1948: it can be inferred therefrom that a great fall in the standard height of children took place during the mentioned period: it was doubtless that the war with subsequent destitutions all over Japan was fully responsible for this very unfavourable occurrence.

Table 2. The Decrement of the Height Growth during the War in Japan.

\begin{tabular}{c|cc}
\hline Age & Boy & Girl \\
\hline 6 & $1.0 \mathrm{~cm}$ & $0.8 \mathrm{~cm}$ \\
10 & $2.1 \mathrm{~cm}$ & $2.0 \mathrm{~cm}$ \\
12 & $2.8 \mathrm{~cm}$ & $2.7 \mathrm{~cm}$ \\
14 & $6.1 \mathrm{~cm}$ & $3.1 \mathrm{~cm}$ \\
\hline
\end{tabular}

From the above can be observed more decrease in the standard beight for boys than for girls. From other available data, it can be well surmised that the year 1946, one year after the termination of war, showed the minimum standard height which was worse than the abovegiven figures (15). In comparison with Table 1 , it can be noticed that $50 \%$ of the increment gained during 39 years in the prewar time was lost within one forth of the period. The more decrease in standard height was proportionately noted for children of the higher age: in case of a boy of 14, a greater decrease was noted than the increase shown during 39 years in the prewar time; such downward tendency in the secular change was quite unprecedented ever since the initial statistic collection made by the Education Ministry of Japan. After the termination of the Russo-Japanese war(1904-1905) and during the period of the world-wide economic panic that continued thereafter for several years, none of such unfavourable effects were recorded on the physical growth of children: on the contrary a certain continuous slight high increase was even shown during the period, the fact of which might have constituted a misleading idea that the social economic change had very little relation with the physical growth. The aforesaid secular changes in height therefore clearly show the inestimable great influence caused by the great war. The same phenomena were also noticed in Germany where the height growth was considerably lowered, but with the fact that children of lower age suffered so much less.

On the other hand, the phenomena shown by Table 2 seem to conflict with the findings by Freund, who, on the comparison of the height and weight of the postwar children of 1 
to 6 in Köln (Cologne) and München (Munich) for the period 1945-1948 with the statistical figures for the previous years, gives many illustrations which show that the physical growth was not retarded under the influence of war, but rather accelerated; he denies the nutritionism that the acceleration phenomena come from nutrition (10). However, these two different facts do not contradict each other for the reason that Freund's investigations were made on infants and children of 1-6, while the figures given in Table 2 are based on children of higher ages than 6. In view of the established fact that children of lower ages suffered so much less, it is more than probable that the same phenomena as pointed out by Freund could have also been traced in Japan. Well then, what is the particular cause of this less or the least influence of the war on children of lower age than 6 ? For this, Freund says that it is due to the fact that susceptibility against stimuli is generally so much weaker for children of lower age (10); in other words, children of higher age than 6 are more susceptible of the complex stimuli brought by the confused environment during and after the war, with the resultant repression or hindrance of their normal physical development; whereas upon infants and children of 1 to 5 whose central and autonomic nerve systems do not mature with far less sensibility, such circumstantial stimuli would usually act in a reverse way and cause acceleration in growth: this accords with an application of Arndt-Schultz's theory that the weak stimuli accelerate the function of the organism while the strong stimuli repress it, the principle of which has a great significance with the acceleration phenomena under discussion, as pointed out by Bennholdt-Thomsen (5). In short, the above-mentioned findings in both Japan and Germany confrrm that the physical development of a human organism may show not only acceleration but also retardation in growth, depending on the social, economic and historical conditions, and this shows very plainly that a human body is very plastic, and it is no other than the theory treated as the premise of the civilization that defines and controls the human being.

(c) Recovery in the postwar time: The speedy recovery of height increase after the war was no comparison with the secular records in the pre-war time: to make the situation clearer, the secular changes covering the three periods of 1900-1920, 1922-1939 and 1948-1955 are cited for comparison as per Table 3 given below:

Table 3. The Increase in Height on a 10 Year Basis, in Japan.

\begin{tabular}{cc|cccc}
\hline \multicolumn{2}{|c|}{ Year } & \multicolumn{2}{|c}{ Boy } & \multicolumn{2}{c}{ Girl } \\
\hline (I) $1900-1930$ & 14 years old & 6 years old & 12 years old & 6 years old \\
(II) $1922-1939$ & $0.69 \mathrm{~cm}$ & $0.09 \mathrm{~cm}$ & $1.25 \mathrm{~cm}$ & $1.39 \mathrm{~cm}$ \\
(III) $1948-1955$ & $2.22 \mathrm{~cm}$ & $1.06 \mathrm{~cm}$ & $1.77 \mathrm{~cm}$ & $1.42 \mathrm{~cm}$ \\
\hline
\end{tabular}

All the figures are worked out by the approximate formula as calculated on a 10 year basis: linear equation thus adopted is considered most adequate and its gradient shown denotes the increase in height on one year basis (15). From the above list, it can clearly be seen that the height for boys of 6 to 14 and girls of 6 to 12 was increased by leaps and bounds during the postwar period of 7 years from 1948 to 1955, showing in case of boy of 14 about 11.7 times and 3.6 times the increase of the 2 pre-war periods (I) and (II) respectively; this fact leads to the conclusion that the acceleration in the physical growth of Japanese children is now being considerably multiplied at present; the speed of this secular acceleration is found pro- 


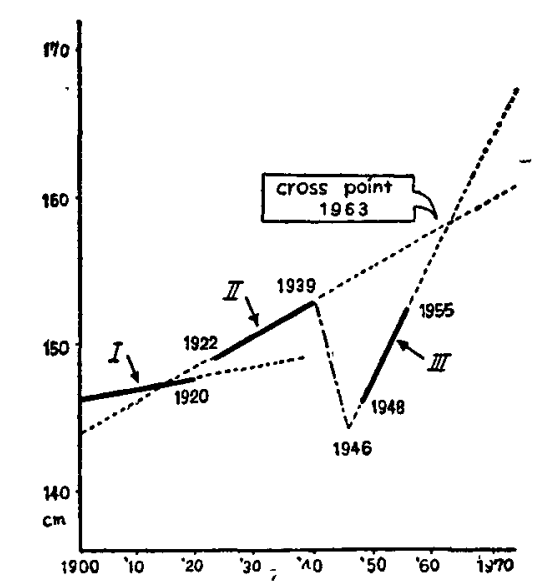

Fig. 1.

Renuarks: The sold line denotes the approximate or average physical growth during the three periods I. 1900-1920, II. 1922-1939 and III. 1948-1955; the dotted line shows the estimated developments in the previous and the following years (15). portionately higher for children of more developmental potentiality, as shown by Figure 1 given below; boys of 14-15 and girls of 12-13 show the maximum rate of acceleration in height increases: and proportionately less acceleration is shown on orher ages than the said ages of highest potentiality. It is very interesting to see an apparent 'Vorverlegung' that the highest potentiality age is now changed to 14 of the present time from 15 of the prewar time for boys and to 12 from 14 for girls.

Table 3 clearly shows that the tempo of the secular acceleration phenomena which usually require a fairly long period before they are put into a proper shape, was not noticeable during the prewar time, and the question is the abrupt sharp upward curve after the war, the fact of which seems to have two main causes: one of them is the outcome of the secular acceleration phenomena and the other is what is termed "Repulsion Effect" (Rückschlag) (15). It can be well surmised that the human organism, the normal development of

which had been greatly hindered due to the very adverse general economic condition during the war and some years after that, gradually gained the restoration capacity to make up for the leeway immediately after the improvement of the living environment and acted along with the effect of the secular acceleration, to simply make the growth speedier. One whose theory is to attribute the cause of the physical development solely to the post-war phenomena, sees the only one side of the actual cause from the repulsion effect view-point and overlooks the other combined factor of acceleration phenomena behind it. So far as the upward curve of the postwar acceleration is concerned, it is not adequate to discuss the fact from the one-sided viewpoint; the repulsion effect and the acceleration phenomena are distinguished from each other and should be treated as two independent factors $(10,15)$.

The above diagram covers the secular change in the height growth of the Japanese boys of 14 , showing recovery in the post-war time. The recovery up to the pre-war level is figured to take place in the year 1963 on the cross point of the two dotted lines, as shown in Figure 1. So far as the absolute height growth value is taken into account, a number of facts confirm its recovery up to the prewar level or ever higher. On the other hand it can be concluded that if it had been for no occurrence of the great war, the height growth would have been possibly developed up to the indicated limit on the dotted line II or even more. However, the existing facts do not show this presumed development on children of any age: if applied by the theory of the developmental acceleration phenomena, the heights of Japanese children of today have not as yet been restored up to the pre-war standards, which might have been considerably higher today.

In short, there is no complete removal of the post-war influence in Japan. The crossing 
of the two dotted lines in II and III,quite apart from the difference in age, may take place sometimes after 1960; if this is realized, it may afford a unique opportunity of observing the actual and more definite post-war transition from the viewpoint of the acceleration phenomena.

2. Developmental gradient in height growth:

This subject is now being discussed briefly as follows: the comparative data collected for 1954 show that the height average in the urban areas is greater than that in the rural districts for children of both sexes on all ages, causing an apparent sharp gradient between the two different regions, as shown in Table 4: more height difference is observed on children of great cities than those of agricultural and fishing villages. In the Figure 2 given below, such discrepancies are illustrated (under the classification of certain prefectures in Japan) in comparison with the average height of all Japan: these are based on a boy of 14 according to the

Table 4. Height Differences between the Urban Areas and the Rural Districts for Children of Both Sexes.

\begin{tabular}{r|cl}
\hline Age & Boy & Girl \\
\hline 6 & $1.0 \mathrm{~cm}$ & $0.9 \mathrm{~cm}$ \\
10 & $1.2 \mathrm{~cm}$ & $1.4 \mathrm{~cm}$ \\
12 & $1.6 \mathrm{~cm}$ & $1.9 \mathrm{~cm}$ \\
14 & $1.9 \mathrm{~cm}$ & $1.6 \mathrm{~cm}$ \\
\hline
\end{tabular}

Fig. 2. Discrepancies in Height Covering Ten (10) Prefectures in Comparison with Average Height of All Japan: $153.6 \mathrm{~cm}$., for the boy of 14 years old.

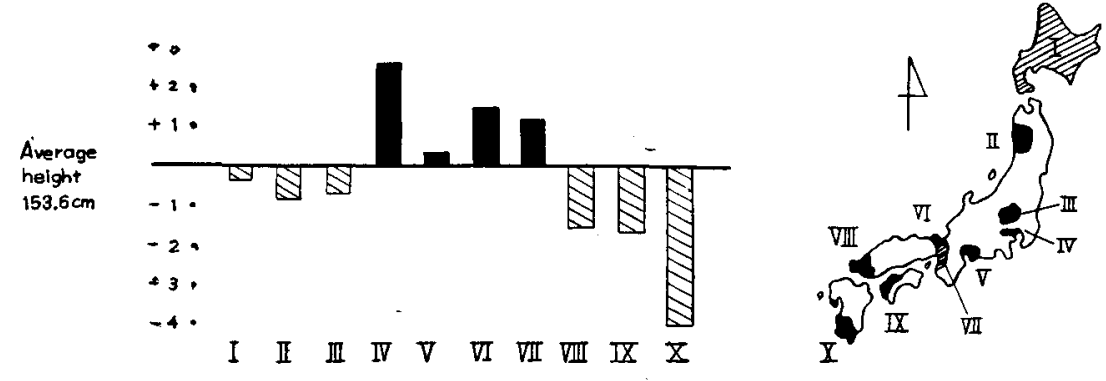

\begin{tabular}{ll|lcrc}
\hline Prefecture & $\begin{array}{l}\text { Average } \\
\text { Height }\end{array}$ & Difference & $\begin{array}{c}\text { Average } \\
\text { Temperature }\end{array}$ & $\begin{array}{c}\text { Population Pressure } \\
\text { Quotient in 1950^ }\end{array}$ \\
\hline I & Hokkaido & $153.2 \mathrm{~cm}$ & $-0.4 \mathrm{~cm}$ & $6.0^{\circ} \mathrm{C}$ & 101 \\
II & Akita & $152.8 \mathrm{~cm}$ & $-0.8 \mathrm{~cm}$ & $10.4^{\circ} \mathrm{c}$ & 154 \\
III Gunma & $152.9 \mathrm{~cm}$ & $-0.7 \mathrm{~cm}$ & $13.1^{\circ} \mathrm{C}$ & 127 \\
IV Tokyo & $156.3 \mathrm{~cm}$ & $+2.7 \mathrm{~cm}$ & $14.0^{\circ} \mathrm{C}$ & 48 \\
V Aichi & $154.0 \mathrm{~cm}$ & $+0.4 \mathrm{~cm}$ & $14.4^{\circ} \mathrm{C}$ & 81 \\
VI Kyoto & $155.2 \mathrm{~cm}$ & $+1.6 \mathrm{~cm}$ & $13.9^{\circ} \mathrm{C}$ & 96 \\
VII Osaka & $154.9 \mathrm{~cm}$ & $+1.3 \mathrm{~cm}$ & $15.1^{\circ} \mathrm{C}$ & 58 \\
VIII Yamaguchi & $152.0 \mathrm{~cm}$ & $-1.6 \mathrm{~cm}$ & $15.2^{\circ} \mathrm{C}$ & 110 \\
IX Ehime & $151.9 \mathrm{~cm}$ & $-1.7 \mathrm{~cm}$ & $14.9^{\circ} \mathrm{C}$ & 134 \\
X Kagoshima & $149.6 \mathrm{~cm}$ & $-4.0 \mathrm{~cm}$ & $16.7^{\circ} \mathrm{C}$ & 167 \\
\hline
\end{tabular}

$\star \frac{\text { local population }}{\text { local income }} \div \frac{\text { national population }}{\text { national income }} \times 100=$ local population pressure quotient (as for above)

Remarks: The above calculation is made on national population pressure quotient being 100 . 
statistics for 1956. As confirmed by Bennholdt-Thomsen through his gigantic collected data $(3,4,5,6)$ the developmental gradient has more inclination to the urban areas than to the rural districts; it can particularly be noticed that the gap between Tokyo ( $35^{\circ} 40^{\prime}$ in latitude) and Kagoshima $\left(31^{\circ} 30^{\prime}\right)$ is so great that the height difference is as much as $6.7 \mathrm{~cm}$. for a boy of 14 and $5.9 \mathrm{~cm}$. for a girl of 12, and the fact fully supports a number of theories that the climatic differences do not constitute an exclusive factor in determining the acceleration phenomena; the statistics show that the height growth is proportionately greater for the prefecture having more larger cities or less population pressure quotient value, and this speaks itself that there is a close relationship between the urbanization phenomena and the acceleration phenomena; the selective processes in emigration to the urban areas may suggest a genetic factor of acceleration phenomena (16).

\section{ACCeleration in Maturity With 'VORVERLEGUnG'}

In connection with physical maturity, two factors: the constitutional conversion age and the precociousness of sexual function are generally considered for observation (21). However, viewed from the theory of acceleration phenomena, each has its own forwarding tendency in time. Here below is given a summary of observations made on the latter, particularly the acceleration in the menarchical age: the existence of this tendency is a very well known fact fully observed in all the civilized countries; in Europe, Backmann's assertion is very significant: he stresses the relationship of this tendency with the acceleration of menarche as well as the retardation of menopause, alluding as far as to the possible prolongation of both the sexual life and the natural human life (2). In Japan ever since 1884, quite a number of studies with evidential data have been reported mainly by physicians, now to make it commonly known that the menarchical age has considerable 'Vorverlegung'. From these data, it can be surmised that the average menarchical age was approximately 14.5 to 15 for the period of 1890-1910 and 14 to 14.5 for 1920-1940 (all in the prewar time), while the age has become approximately 13 in the postwar time; there are many cases in which the average age has proved to be as early as 12 years and 11.6 months for a girl of the 2 nd grade of a junior high school (21). The average menarchical age difference between mother and daughter is about

Table 5. Menarchical Age.

\begin{tabular}{l|l}
\hline Mother & $14: 6$ \\
1st daughter & $13: 10$ \\
2nd daughter & $13: 9$ \\
3rd daughter & $13: 5$ \\
\hline
\end{tabular}

8 to 9 months: the investigations made on 118 families in Osaka reveal that there is an apparent secular acceleration in the menarchical age, the similar fact of which is also reported over the observations made in Germany (17). Particulars are given in the following Table 5.

As regards the developmental gradient phenomena in sexual maturity, certain observations reveal the following facts: Item Nos. (1) to (4) wherein the relevant discrepancy-factors are pointed out for explanation.

(1) Regional aspects: There is a remarkable difference noticed between the urban areas and the rural districts, the formar showing a higher rate of acceleration than the latter: comparative data on a girl of the first year grade of a junior high school show that the number of menstruated girls is of such high rate as $67.3 \%$ in the central part of Osaka City and $75.4 \%$ in Toyonaka City (Osaka Prefecture) where the living status and condition of the residents 
is considered the second highest of the whole Japan, while it is lowered to as small a percentage of 40.6 in one of the farming villages of Okayama Prefecture (western part of Japan proper). Similar records are also applicable to the Tokyo Metropolis, where the number of menstruated girls is found the highest in the municipal wards, followed by the local cities and towns and rural districts on the gradual less percentages in the respective order; it is also found that the number of menstruated girls has become higher for girls of completion of the highest grade of a primary school. Table 6 given below may serve for reference:

Table 6. The Number of Menstruated Girls at the Time of Completion of a Primary School in Tokyo in 1957.

\begin{tabular}{l|l}
\hline Municipal wards & $20.3 \%$ \\
Local cities & $17.9 \%$ \\
Rural districts & $13.7 \%$ \\
\hline
\end{tabular}

In the same urban area, the central district has more menstruated girls than the localities as shown in Figure 3 given below (21).

Fig. 3. The Number of Menstruated Girls at the Time of Completion of a Primary School on the Municipal Wards of Tokyo Metropolis in 1957.

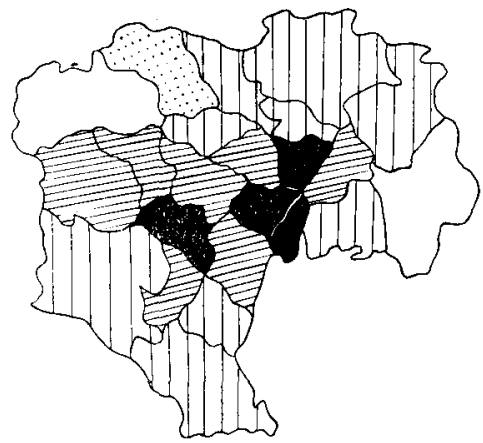

Shows $26 \%$ and over (maximum $35.7 \%$ )

Shows $21-25 \%$

(11i) Shows 16-20\%

Shows $15 \%$ and under (minimum $8.3 \%$ )

Shows unknown

(2) Parents' school career: It is of the general trend that for daughters whose parents' school career is high, their sexual function mature early in a proportionate degree.

(3) Parents' vocation: Sextual maturity difference among children depends on the different calling on the part of parents: it is generally inferred that acceleration is the case with daughters whose parents are administrators of some specialistic lines, while retardation is noticed with those whose parents are semi-skilled or non-skilled workers.

(4) Home life: Better economical condition on the part of the family constitutes another factor in acceleration of the sexual function of children.

It is pointed out that the item Nos. $2,3 \& 4$ have an interrelation with one another: in short, for daughters whose parents' social status is high, the maturity of their sexual function comes earlier (16).

\section{Some Views of Acceleration Phenomena}

The findings given in the preceding paragraphs dealing with secular acceleration phenomena and developmental gradients can neither fully explained within the independent sphere of the nutritionism or the endocrinological theory, nor is it possible to give any adequately explicit answer by scrutinizing the causes of the natural enviromental factors, such as climatic conditions, etc. There is no denying the fact that the human body development has much to 
do with the growth and sex hormones, but it is incorrect to attribute the physical growth to their functions only, by the reason that these hormones act as an accelerating agency and do not constitute the cause of the body development: it is also a common notion that the endocrine glands do not make the organism mature, but the latter helps the former to accelerate maturity of the human body. As already stated, the acceleration phenomena have doubtless a close bearing on the urbanization of the present age; in this connection, it can safely be concluded, apart from many of the different views and assertions as to the actual factors of urbanization, that the current urban community brought up by the modernization into an institutional society has a great influence directly upon the psycho-biological organization of the human inhabitants within that specific area (9), and thus promote acceleration in growth and also the 'Vorverlegung' in maturity of the human organism, as this may be termed "urban izing trauma" $(3,6,20)$.

This refers also to various theories attempting to explain the developmental gradient phenomena from the view-point of urban anthropology: among them are "mental acceleration" caused by the urban stimuli (20) and "biological unnaturalization" in the urban life (12), and also "human typicalization" which professes that in the course of the formation of urban communities there would take place the selective emigration of certain human type characteristic of some typical psycho-biological organizations, the movement of which continues for accumulation until its work is completed (3). On the other hand, it is more than probable that these acceleration phenomena must have affected the psychological aspect of the human being. Investigations have already shown that a boy of 15 and a girl of 14 in 1956 are almost equivalent in height to the children of 17 years and 7 months and 20 years of age in 1900 respectively (15); this sort of increased height growth in the post-war time signifies not only a more change in bodily constitution but also the definite alteration of the way by which to view and meet the environmental world, with the consequence that the post-war children can gain experience quite different from what the pre-war children might have had: this would naturally raise a question as to whether or not it is proper to treat a 15 years old boy of the post-war time as a boy of 17 of the pre-war time. However, the psychological and medical researches have already proved that the acceleration in bodily growth does not keep pace with the acceleration working on other areas of human personality. Many findings based on the records of electrocardiographic diagnosis (23) give a very important suggestion that the physiological organization of such accelerated juvenile is generally too weak to meet the excessive environmental demands that come from the bodily appearance like an adult: moreover, many psychologists point out very clearly the inconsistency between the two sides of the human being. What is the correct status that the accelerated juvenile should have or be given? This is the very problem that calls for urgent solution through further researches on the part of psychologists and pedagogists, in view of the fact that the ratio of acceleration in the human growth is tending upwards along with the very high speed at which further urbanization of the present world is now being performed (19). A mere discussion with the conclusion that the inconsistency between the spiritual and physical sides of the human being is the outcome of the unbalanced acceleration of one organization over the other, is one thing for itself, and the other more important problem is to make it clear on the evidential data to see whether this inconsistency is over the limit or not, since should the answer be given on the affirmative side, 
it would be quite detrimental to the formation of human personality. Many psychologists in Japan are now tracing up the fundamental causes of the said inconsistent phenomena as well as the existing type of the juvenile delinquency, with determination to define characteristics of both accelerated and retardated juveniles in not so long distant future.

\section{REFERENCES}

1. Aron, A. H. Wachstum und Ernährund. Biochem. Zb., 1917, 30.

2. Backmann, G. Die beschleunigte Entwicklung der Jugend. Acta Anatomica, 1948, 4, 421-480.

3. Bennholdt-Thomsen, C. Die Entwicklungsbeschleunigung. Erg.d.inn.Med.u. Kinderhlk., 1942, 62, 1153-1237.

4. Bennholdt-Thomsen, C. Ưber das Accelerationsproblem. Z. f. menschl. Vererb. und Konstitutionslehre. 1952, 30, 620-634.

5. Bennholdt-Thomsen, C. Entwicklungswandlung. Stud. Gener., 1951, 5, 288-290.

6. Bennholdt-Thomsen, C. Das Grossstadtkind. Stud. Gener., 1955, 2, 127-134.

7. Bolk, L. Das Ploblem der Menshwerdung. Jena: 1926.

8. Conrad, K. Der Konstitutionstypus als genetisches Problem. Berlin: 1941.

9. Eickstedt, E. Bevölkerungsbiologie der Grossstadt. Stuttgart: F. Enke, 1941.

10. Freund, J. Der gegenwärtige Stand der ACceleration bei Neugeborenen und Kleinkindern. Z.f. Kinderhlk., 1950, 67, 592-614.

11. Gehlen, A. Der Mensch. Seine Natur und seine Stellung in der Welt. Bonn: Athenäum, 1950.

12. Hellpach, W. Mensch und Volk den Grossstadt. Stuttgart: F. Enke, 1952.

13. Koch, E. W. Ủber die Veränderung des menschlichen Wachstums in ersten Drittel des 20 Jahrhnuderts. Leipzig: 1935.

14. Lenz, W. Über die wandlungen menschlichen Wachstums in der Gegenwart. Z.f. menschl. Vererb. und Konstitutionslehre., 1943-44, , 543576.

*15. Maeda, Y. and Sawada, A. Study of accelera- tion phenomena: I. The secular acceleration in Japanese younger generations. Jap. Psychol. Review, 1957, 1, 159-178.

*16. Maeda, Y., Sawada, A. and Okazaki, H. Study of acceleration phenomena: III. The developmental gradient phenomena. Jap. Psychol., Rev. 1959, 3, 85-99.

17. Pessler, G. Untersuchung über den Einfluss der Grossstadt auf die Kopfform. Sowie Beiträge zur Anthropologie und Stammeskunde Hannovers. Z. Morph. u. Anthrop., 1938, 38.

18. Portmann, A. Biologische Fragmente zu einer Lehre vom Menschen. Basel: Benno Schwabe, 1951.

19. Rössler, W. Jugend im Erziehuntgsfeld. Düsseldorf: Schwann, 1957.

20. Rudder, B. de. Allgemeinprobleme des Wachstumsalters. In Thiel: Gegenwartsprobleme der Augenheilkunde. Leipzig, 1937.

$\star 21$. Sawada, A. Study of acceleration phenomena : II. The acceleration in maturity with priority tendency. Jap. Psychol. Rev. 1958, 2, 282-302.

22. Schachtel. E. G. Metamorphosis. New York, 1959, f. 156.

23. Schmidt-Voigt, J. Wesenszüge in Elektrokardiogramm des accelerienten Jugendlichen. Z.f. Kinderhlk., 1948, 65, 394-416.

24. Thomae, H. und Hagen, W. Deutsche Nachkriegskinder. Methoden und erste Ergebnisse der deutschen Längsschnittuntersuchungen über die körperliche und seelische Entwicklung im Schulkindalter. Stuttgart: G. Thieme, 1954.

25. Zeller, W. Konstitution und Entwicklung. Göttingen: Grefe, 1957.

* Written in Japanese.

Akira Sawada (澤田 昭 1928- ) Graduated from Osaka Univ. in 1954; 1955-, Assistant, Department of Psychology, Osaka University.

Toshitake Amano (天野利武 1904- ) Graduated from Tokyo Univ, in 1927. 1927-1945, Assistant to Professor, Department of Psychology, Keijo Univ.; 1943, Litt. D., Tokyo Univ.; 1946-1953, Superintendent of Kyoto Prefecture Educational Board. 1953- , Professor, Department of Psychology, Osaka University. Yoshiaki Maeda (前田嘉明 1916-) Graduated from Tokyo Univ. in 1940; 1941-1948, Research Fellow, Tokyo Univ.; 1949-1952, Assistant Professor, Tokyo Christian Women's College; 1952-54, Univ. of Hannburg; 1952-, Assistant Professor, Department of Psychology, Osaka University. 